\title{
Erratum to: Bacterial Diversity Patterns Differ in Soils Developing in Sub-tropical and Cool-Temperate Ecosystems
}

\author{
Shankar G. Shanmugam ${ }^{1,2}$ - Zenaida V. Magbanua ${ }^{1,2}$ • Mark A. Williams ${ }^{5}$. \\ Kamlesh Jangid $^{4}$ - William B. Whitman ${ }^{3}$ - Daniel G. Peterson ${ }^{1,2}$ - William L. Kingery ${ }^{1}$
}

Published online: 12 December 2016

(C) Springer Science+Business Media New York 2016

Erratum to: Microbial Ecology

DOI 10.1007/s00248-016-0884-8

Due to typesetting error, the article title was mistakenly amended to "Bacterial diversity patterns differed in two developing ecosystems". The original article was corrected.

The online version of the original article can be found at http://dx.doi. org/10.1007/s00248-016-0884-8.

\section{Shankar G. Shanmugam}

sg383@msstate.edu

1 Department of Plant and Soil Sciences, Mississippi State University, 117 Dorman Hall, Mississippi State, MS 39762, USA

2 Institute for Genomics, Biocomputing \& Biotechnology, Mississippi State University, Mississippi State, MS 39762, USA

3 Department of Microbiology, University of Georgia, 527 Biological Sciences, Athens, GA 30602, USA

4 Microbial Culture Collection, National Centre for Cell Science, Pune 411007, Maharashtra, India

5 College of Agriculture and Life Sciences, Virginia Polytechnic and State University, Horticulture, 301 Latham Hall,

Blacksburg, VA 24060, USA 